\title{
Quantity-sensitive stress and syllable weight in Paiwan
}

\author{
Shih-chi Stella Yeh \\ National Kaohsiung Normal University, Taiwan \\ shihchiyeh@nknu.edu.tw
}

\begin{abstract}
This study reexamines the assignment of stress in the Paiwan language spoken in several central Paiwan villages, which differs from the other communalects in treating the central vowel, schwa $/ ə /$, as a weak element with regards to the syllable and stress. Contrary to previous quality-sensitive analyses, this paper explores new data and argues for a quantity-sensitive account based on a variable weight system for closed syllables. It is shown that the inherently non-moraic coda consonants gain weight only to satisfy the requirement for an appropriate foot head. The special behavior of schwa in stress assignment also parallels to other phonological evidence in Paiwan such as its distributional restriction.
\end{abstract}

Keywords: quantity sensitivity; coerced weight; stress; schwa; syllable weight

\section{Introduction}

This paper aims to reveal the pattern of word-level stress in several central Paiwan communalects, ${ }^{1}$ and argues for a quantity-sensitive account that relies on differing weights for coda consonants. The paper not only shows crucial linguistic facts regarding stress, but also proposes an analysis that captures the phonological system of the language. Paiwan is an Austronesian language spoken in the southern mountainous area of Taiwan, mainly in Pingtung and Taitung counties. In a few of the geographically central Paiwan villages, ${ }^{2}$ the communalects display a stress pattern which

${ }^{1}$ In this paper, the word communalect is used to refer to the language spoken in a given region, such as a village. The Paiwan language spoken in one village might be slightly different from another; however, the difference between them is not significant enough to facilitate subgrouping. Therefore, instead of dialect, communalect might be a more neutral term.

${ }^{2}$ Those villages include Piuma and Kazangiljan, which will be specifically mentioned in this study, and others like Qapedang, Kazazaljan, Ulaljuc and Kaviyangan. Cheng's (2016) geolinguistic study has a detailed but different survey. This patterning of stress is also displayed in a few more villages in Taitung County which were established by people who moved out of these central villages long ago. 
partially differs from most other Paiwan communalects. While the majority of Paiwan communalects have regular penultimate stress and treat all vowels the same in terms of stress assignment, these particular communalects disfavor schwa /o/ as the head of prominence, resulting in shifted stress within the last two syllables. More specifically, penultimate stress is the pervasive pattern for the Paiwan language in general; due to phonological or morphological reasons, stress on the final syllable only appears in words with underlying vowel hiatus at the right edge, monosyllabic words, and concatenations of a prefix/infix plus a monosyllabic word. However, in the communalects specified above, more factors must also be considered: these communalects additionally avoid stress on penultimate schwa, instead shifting it to the final full vowels $/ \mathrm{i} \mathrm{u} \mathrm{a/.} \mathrm{If} \mathrm{both} \mathrm{the} \mathrm{penultimate}$ and final syllables contain schwas, the location of stress depends on syllable structure - a closed syllable with schwa receives stress. Thus, the structure of the syllable and its weight are both involved in stress placement.

This study disagrees with previous analyses that rely on a qualitysensitive or sonority-driven account, and argues for quantity-sensitivity by providing new data to show that syllable weight plays a crucial role in specific Paiwan communalects. In Chen (2009) and Yeh (2011a), the placement of stress is attributed to the quality or sonority of vowels when schwa is involved. Specifically, their claim is that stress favors peripheral (non-central) vowels /i u a/ and dislikes schwa /ə/; therefore, stress never falls on a schwa if a peripheral vowel is available within the metrical domain. In contrast, it is argued here that word stress is sensitive to the exact quantity of a syllable; thus, having a weight distinction (non-moraic or moraic) among coda consonants is necessary. To be more precise, coda consonants are inherently non-moraic; they are weighted only when they need to satisfy the requirements for stress. Thus, a distinction in weight is needed in which diphthongs and coalesced vowels are heaviest, followed by open and closed syllables with / i u a/ nucleus and closed syllables containing schwa, and open syllables with schwa are the lightest. New data are provided to show the crucial distinction between open and closed syllables with schwa. In the following, section 2 sketches a general picture of Paiwan phonology including phonemes, phonotactics, and syllable forms. Section 3 describes stress in the above-mentioned Paiwan communalects, together with new data. Section 4 argues that stress in Paiwan is sensitive to syllable quantity, and an analysis within the framework of Optimality Theory (McCarthy \& Prince 1993; Prince \& Smolensky 2004) is provided which clarifies the interaction between foot form and syllable weight. Section 5 further discusses the analysis, demonstrates similar patterns in other Austronesian languages, and concludes this paper. 


\section{A sketch of Paiwan phonology}

In the process of stress assignment in Paiwan, different phonological units interact with each other, necessitating some knowledge of Paiwan phonology in order to understand the assignment of stress. Apart from the phonemic vowels and consonants, the distribution of segments, the structure of syllables, and the rules that influence syllables and that also affect the location of stress are depicted here. Although most of the phonology described here does not differ from previous work (Ho 1977; 1978; Ferrell 1982, among others), this paper does offer additional detailed remarks.

Paiwan has four vowels /i u ə a/, without any phonemic distinction in vowel length. Ho $(1977,606)$ considers / / / a restricted vowel because it cannot occur in word-initial or word-final position. Despite the existence of a few words that begin or end in $/ \mathrm{\partial} /,{ }^{3}$ my observation is basically similar to Ho's regarding schwa's behavior with regard to phonotactics and metrical patterning. The number of consonants ranges from 20 to 23 due to the replacement or merging of sounds in different communalects. The following consonant inventory is from Piuma Paiwan: / $\mathrm{p} \mathrm{b} \mathrm{t} \mathrm{d} \mathrm{d} \mathrm{c} \mathrm{f} \mathrm{k} \mathrm{g} \mathrm{q} \mathrm{v} \mathrm{s} \mathrm{z} \mathrm{R} \mathrm{ts}$ $\mathrm{m} \mathrm{n} \mathrm{y} K \mathrm{lr} \mathrm{w} \mathrm{j} /$. Regular sound correspondences can be found between the communalects; for example, /q/ and /R/ in Piuma are replaced by / $\mathrm{P} /$ and $/ \mathrm{r} /$ respectively in Kazangiljan. A more explicit description can be found in Ho (1978), which illustrates correspondences and historical derivations from Proto-Austronesian (PAN) based on the five different communalects located in the northern, central, southern and eastern areas of Paiwan. In addition, Cheng (2016) offers a recent geolinguistic survey, in which correspondences between different villages are clear.

The structure of the syllable is generally straightforward. Complex syllable margins (onset and coda clusters) are not tolerated, so the form of a syllable is mostly confined to $\mathrm{CV}(\mathrm{C})$. The onset position allows any consonant in the inventory, ${ }^{4}$ but the coda position is somewhat more restrictive - a word-final coda consonant can be any consonant but word-internal

${ }^{3}$ In Sinvaudjan (a southern village), the words /ənəm/ 'six' and /gadə/ 'mountain' begin or end with a schwa, though it is /unəm/ and /gadu/ in most communalects. These exceptions could be the result of a sporadic sound change from $/ \mathrm{u} /$ to $/ \mathrm{\partial} /$, as this irregular $/ \mathrm{u} / \sim / \mathrm{\partial} /$ correspondence can be seen in several communalects. Additionally, in the central communalects targeted, words ending in schwa such as /quরinəyə/ 'Pouzolzia elegans (plant species)' can be found.

${ }^{4}$ Syllable onsets usually do not begin with glides $/ \mathrm{w} /$ or $/ \mathrm{j} /$ except the word $/ \mathrm{ki}$ jaja/ 'to pick, pluck'. Other words containing glide onsets are mostly loanwords from Japanese such as /jasi/ 'coconut' or /wara/ 'dried rice-straw'. 
codas only allow nasals and glides. In fact, Paiwan does not have genuine coda consonants in word-medial position. Although nasals and glides are observed in synchronic data, glides can be assumed to derive from underlying vowels. Medial nasal codas are considered the result of deletion of a following schwa, based on the surface appearance of final stress in the central communalects, e.g., [va.yə.sár] $\rightarrow$ [vay.sár] 'handsome'. Other communalects, such as Sinvaudjan, maintain regular penultimate stress on the surface in these words, e.g., [váy.sar]. The other form of word-internal coda, which appears in words with fossilized reduplication, is also the outcome of schwa deletion word-internally, e.g., / yisənis/ [ni.sə.yís] 'beard' or [nis.nís] in fast speed. To put it another way, no surface CVC syllables can be found word-internally in synchronic data except those ending in nasals / $\mathrm{m} \mathrm{n} \mathrm{y/} \mathrm{or} \mathrm{glides} \mathrm{/} \mathrm{j} /$; otherwise, word-internal CV syllables are the norm. ${ }^{5}$ However, a more complex system of syllable structure emerges when the effect of underlying vowel hiatus is examined. This study assumes that clusters of different vowels combine and form diphthongs in natural speech tempo, such as /kəvava-u/ [kə.va.váw] 'drink wine (IMP)', while clusters of identical vowels coalesce, as in /pu-vasa-an/ [pu.va.sán] 'taro field' (Yeh 2011a). ${ }^{6}$ In the former case, the concatenation of the two vowels results in a surface diphthong via glide formation, in which the glide still retains its weight. ${ }^{7}$ In the latter, underlying identical vowels become a single surface vowel through coalescence, though the syllable weight of the two vowels is preserved as well. As will be explained in detail below, the

${ }^{5}$ Word-internal codas which are neither glides nor nasals can be observed in fossilized (or lexicalized) reduplication, in which the root $\left(\mathrm{C}_{1} \mathrm{~V}_{1} \mathrm{C}_{2}\right)$ has undergone full reduplication $\left(\mathrm{C}_{1} \mathrm{~V}_{1} \mathrm{C}_{2} \cdot \mathrm{C}_{1} \mathrm{~V}_{1} \mathrm{C}_{2}\right)$ and become fossilized, and thus no longer identifiable. Examples include /viqəviq/ 'ripple', /yisənis/ 'beard', and /katsakats/ 'trousers'. Note that an intervening vowel, which is usually a schwa or a copy of a neighboring vowel, often appears between the two identical CVC syllables to avoid illegitimate word-internal codas. However, in natural (faster) speed, the vowel would be dropped in some cases.

${ }^{6}$ Dissimilar points of view toward vowel hiatus can be seen in the literature. Vowel sequences are always treated as hetero-syllabic in Ferrell $(1982,7)$. Ho (1977) makes vowel clusters with falling sonority (e.g., /au/ or /ai/) simply hetero-syllabic (e.g., [a.u] or [a.i]), and those with rising sonority (e.g., /ua/ or /ia/) separated by an inserted glide (e.g., [u.wa] or [i.ja]). On the other hand, Egli (1990, 7-10) treats vowel clusters with falling sonority (/au/ or /ai/) as tauto-syllabic diphthongs, rather than monophthongs in separate syllables, citing speech tempo. Also, Chen (2006; 2009) treats vowel clusters as tauto-syllabic diphthongs with glide formation.

${ }^{7}$ Refer to Yeh (2011b) for a detailed discussion of the distinction between derived glides and underlying glides and the evidence supporting it. 
syllables thus derived from underlying vowel hiatus crucially differ from the dominant pattern in assigning stress: they attract what would otherwise be penultimate stress when in final position. That is to say, penultimate stress shifts to the ultima when such heavy syllables are in word-final position. The restructuring of the syllable changes its weight, and thus influences the pattern of stress.

Stress in Paiwan generally falls on the penultimate syllable (Ho 1977; Ferrell 1982; Egli 1990). Stress is on the ultima under three circumstances in most communalects: (i) when the final syllable of a prosodic word is derived from underlying vowel hiatus, (ii) when the word is monosyllabic, and (iii) when a prefix/infix is adhered to a monosyllabic root.

In the first situation, underlying non-identical vowel hiatus is repaired by glide formation, making the less sonorous vowel a derived glide as can be seen in (1). Through this process, the $\mathrm{CGV}(\mathrm{C})$ or $\mathrm{CVG}(\mathrm{C})$ syllable inherits two moras from the underlying vowels; therefore, the heavy syllable attracts stress. Acute stress is then placed on the more sonorous segment, but the result is that stress falls on the syllable as a unit. Note that suffixes, such as $-u,-i$, or -an, do not attract stress; instead, stress falls on the penultimate syllable of the prosodic word when attaching to a consonantfinal root, e.g., alap-u [a.lá.pu] 'take (IMP)'.

(1) a. Tauto-morphemic hiatus

$\begin{array}{lll}\text { /sikau/ } & {[\text { ji.káw] }} & \text { 'net bag' } \\ \text { /ki-paiz/ } & {[\text { ki.pájz] }} & \text { 'fan (AV)' } \\ \text { /ma-guat/ } & \text { [ma.gwát] } & \text { 'hoarse' } \\ \text { /qatia/ } & \text { [qa.tjá] } & \text { 'salt' }\end{array}$

b. Hetero-morphemic hiatus

$\begin{array}{lll}\text { /tsapa-u/ } & \text { [tsa.páw] } & \text { 'roast (IMP)' } \\ \text { /kəvava-i/ } & \text { [kə.va.váj] } & \text { 'drink wine (IMP)' } \\ \text { /ra-ruvu-an/ } & \text { [ra.ru.vwán] } & \text { 'nesting place' } \\ \text { /pu-lapi-an/ } & \text { [pu.la.pján] } & \text { 'place of putting hollow grains' }\end{array}$

For underlying hiatus with identical vowels, the two vowels coalesce, and the weight of the two underlying vowels attracts stress within the metrical domain, as can be seen in (2).

(2) Hetero-morphemic identical vowel hiatus

$\begin{array}{llllll}\text { /pu-vasa-an/ } & \text { [pu.va.sán] } & \text { 'taro fields' } & \text { /ka-kəsa-an/ } & \text { [ka.kə.sán] } & \text { 'kitchen' } \\ \text { /kali-i/ } & \text { [ka.lí] } & \text { 'dig (IMP)' } & \text { /vəli-i/ } & \text { [və.lí] } & \text { 'buy (IMP)' } \\ \text { /katsu-u/ } & \text { [ka.tú] } & \text { 'carry (IMP)' } & \text { /kikimu-u/ } & \text { [ki.ri.mú] } & \text { 'come (IMP)' }\end{array}$


In the second and third cases, stress falls on the ultima for different reasons. In monosyllabic words, it necessarily falls on the only stress-bearing unit available. In a monosyllabic root plus prefix or infix, the affix is unable to carry stress in Paiwan; therefore, stress again necessarily resides on the only available unit: the final syllable, which is a monosyllabic root, e.g., $k\langle\partial m\rangle$ an [kə.mán] 'eat (AV)', pa-kan [pa.kán] 'to feed', ma-łaq [ma.fáq] 'to menstruate'. 8

To summarize, Paiwan stress invariably falls in the last two syllables. The default penultimate stress is on the final syllable only when the ultima is a heavy syllable, the word is monosyllabic, or when the penult is a prefix/infix. These patterns, including the shifting of stress to heavy syllables formed from underlying hiatus, hold true for all Paiwan communalects.

\section{A different pattern of stress}

The central communalects in this study contrast with the other communalects in one important regard: they distinguish schwa / / / from other vowels when assigning stress, avoiding it and preferring / $\mathrm{i} \mathrm{u} \mathrm{a/for} \mathrm{stress}$ assignment. In doing so, they furthermore treat final coda consonants in distinct ways. To begin with, (3) compares words with different types of

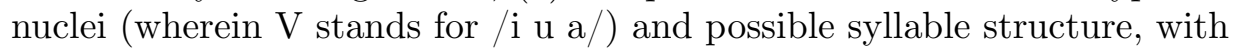
boldfaced type representing stress. (Words with underlying hiatus are excluded here for clarity.)

(3) Comparison of stress in different communalects

\begin{tabular}{|c|c|c|c|c|}
\hline & Full vowels & Final schwa & Penultimate schwa & All schwa \\
\hline central communalects & CV́.CV & Cर́.Cə & Сə.CÉ & Cá.Cə \\
\hline under discussion & CÉ.CVC & CÉ.CəC & Cә.CÉC & Cə.CáC \\
\hline most Paiwan & CV́.CV & CV́.Cə & Cá.CV & Cá.Cə \\
\hline communalects & CÉ.CVC & 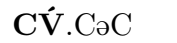 & Cá.CVC & Cá.CəC \\
\hline
\end{tabular}

${ }^{8}$ In most communalects which allow schwa to carry stress, a prefix/infix (that often contains a schwa) is excluded from stress assignment. Thus, even in the central communalects which dislike putting stress on schwa, it is the morphological category that avoids stress, not the schwa in the prefix/infix. However, in contrast to the prevailing pattern, Cheng (2016, 131-132) mentions that in Puljetji village, stress always falls on the penultimate syllable regardless of morphological structure, i.e., whether it is a prefix/infix or root. 
As exemplified in the data above and below, stress is confined to the last two syllables without exception. That is, there are only two positions for stress to reside - either penultimate or final - and the penultimate syllable is the preferred choice in both groups of communalects, though the presence of schwa in that syllable makes it less preferable than the ultima for stress assignment in the central communalects examined here. Word-final coda consonants normally do not influence the placement of stress, unless the syllable nucleus is a schwa. This pattern hints at a dissimilar treatment of coda weight, depending on the nucleus. Following the line that default unmarked stress is penultimate, this overwhelmingly preferred pattern is affected by the nucleus vowel and syllable structure in these central communalects, with the result that stress retreats from schwa if possible, as shown in (4) and (5). Note that the data in (4) demonstrate two things: first, stress falls on the penultimate syllable. Second, the presence of a word-final coda and its manner of articulation has no effect on stress assignment. In other words, an open syllable (CV) equals a closed one (CVC) in syllable weight; therefore, coda consonants have no contribution to quantity and can be considered weightless. The data in (5) show the persistence of penultimate stress in a prosodic word regardless of suffixation.

(4) [kí.na] 'mother' [cá.kit] 'sickle' [pá.na] 'river' [vú.das] 'sand'

[lá.vu] 'ash' [yá.faj] 'saliva' [qú.lu] 'head' [sá.fiq] 'ant'

[vá.li] 'wind' [qú.vaর] 'hair' [ná.ji] 'breath' [vá.qay] 'molar'

(5) /masalu / [ma.sá.lu] 'believe' /lumamad/ [lu.má.mad] 'baby'

/saviki/ [sa.ví.ki] 'betel nut' /mili-milin-an/ [mi.li.mi.lí.nan] 'story'

/talivak/ [ta.lí.vak] 'healthy' /pu-padaj-an/ [pu.pa.dá.jan] 'rice field'

However, stress in the communalects under consideration seeks out an available / $\mathrm{i} \mathrm{u} \mathrm{a/} \mathrm{and} \mathrm{avoids} \mathrm{schwa/o/} \mathrm{within} \mathrm{the} \mathrm{two-syllable} \mathrm{domain}$ from the right edge, as shown in (6), while the rest of the Paiwan communalects treat all vowels as equivalent. The contrast between the relevant communalects (e.g., Piuma) and others (e.g., Sinvaudjan) in this regard is shown in (7). In these data, it is obvious that the central communalects examined in this study (like Piuma) avoid stressed schwa, whereas communalects like Sinvaudjan assign stress to the penultimate vowel regardless of its quality. The central communalects' avoidance pattern is even clearer in suffixation: when a root-final schwa becomes the penultimate nucleus with the addition of a monosyllabic suffix, stress, which would otherwise be penultimate, shifts to the word-final syllable, as shown in (8). Note 
that the imperative suffixes themselves do not attract stress, as shown by comparing p〈ə〉náyul, 'hit (AV)' and payúl-u 'hit (IMP)'.

(6) [kə.rí] 'small' [cə.vús] 'sugarcane' [qa.pə.dú] 'gall' [qə.tfáp] 'chopsticks' [sə.má] 'tongue' [gə.rón] 'throat' [kə.rí $]$ 'sparrow' [tgu.qə.lá $]$ 'bone' [va.kə.lá] 'arrow' [qə.zúp] 'window' [qu.rə.pús] 'cloud' [sa.fə.lúp] 'heavy'

\begin{tabular}{|c|c|c|c|c|c|}
\hline $\begin{array}{l}\text { liuma } \\
\text { rə.rí] }\end{array}$ & $\begin{array}{l}\text { Sinvaudjan } \\
\text { [kó.di] }\end{array}$ & 'small' & $\begin{array}{l}\text { Piuma } \\
\text { [qə.pə.dú] }\end{array}$ & $\begin{array}{l}\text { Sinvaudjan } \\
\text { [qa.pó.du] }\end{array}$ & 'gall' \\
\hline & [có.vus] & 'sugarcane' & [qu.rə.pús] & [qu.ró.pus] & oud' \\
\hline tfáp] & [qá.tsap] & 'chopsticks' & [tu.qə.láK] & [tsu.qá.la $\Lambda$ ] & 'bone' \\
\hline
\end{tabular}
a. táqəd
'sleep (AV)'
taqəd-ú 'sleep (IMP)'
b. pə-lúsəq
'weep (AV)'
lusəq-ú 'weep (IMP)'
c. $\mathrm{v}\langle$ ən $\rangle$ nátəq
'wash (clothes) (AV)'
vatəq-í 'wash (IMP)'

Examination of this pattern leads to the question of how stress is assigned if both vowels in the two-syllable domain are schwa / / /. As stress inevitably has to fall on one or the other, the presence of a word-final coda now becomes a relevant factor: stress falls on the final syllable if it is closed by a consonant as in (9). Otherwise, stress reverts to the preferred penultimate pattern when both the penultimate and final syllables contain schwa and the final syllable is open, as shown in (10), though such data are rare. The asymmetry between (9) and (10) suggests that the word-final coda consonant plays a crucial role in contributing weight to the syllable. However, recall that, as demonstrated by the data in (4), coda consonants are normally of no significance in terms of stress assignment. Their presence only becomes relevant when both possible sites for stress contain schwa/ə/. This apparent inconsistency can be attributed to the greater importance of the requirements imposed on a stress-bearing syllable: the weight contributed by a coda consonant is irrelevant when the penultimate contains one of the vowels /i u a/, which alone satisfy the requirement of a stress bearer. However, when both possible sites for stress contain schwa, which is phonetically shorter and phonologically weaker than the other vowels, the following coda consonant is coerced into gaining weight and helping the defective nucleus. The extra weight tips the balance in favor of assigning stress to its syllable.

\begin{tabular}{|c|c|c|c|c|}
\hline (9) & 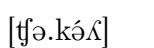 & 'spouse' & [və.Кə.vá K] & 'banana' \\
\hline & [lə.sə́q] & 'tear' & [ţə.mól] & 'grass' \\
\hline & [Кə.lót] & 'lip' & [ma.pə.tóq] & 'break (PV)' \\
\hline & [və.tfə.qál.] & 'short necklace' & [pa.fə.káț] & 'stick on (CAU) \\
\hline
\end{tabular}


(10) [vó.və] 'to sprout'

[l’̀.fə] 'thin'

[á.pə] female juvenile name

[ə̊.Pə] sound meaning disagree

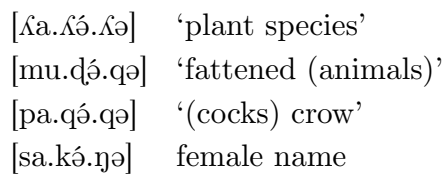

To summarize the data from the central communalects, penultimate stress is prevalent when no schwa is present in the rightmost two-syllable domain. Furthermore, stress avoids falling on schwa/ə/ within the domain unless the last two vowels are both schwa. Under these conditions, stress is assigned to the ultima if it is a closed syllable; otherwise, stress is placed on the penultima by default.

\section{A possible analysis}

This study differs from previous analyses relying on quality-sensitive or sonority-driven accounts of stress, and instead favors a quantity-sensitive analysis for stress in the Paiwan communalects, in which peripheral vowels / i u a/ are heavier than schwa, and a coda consonant contributes coerced weight to help when needed. It further provides an OT account for the data using this analysis, Paiwan is below compared to Takia (Ross 2002), a language with true properties of quality-sensitive (sonority-driven) stress.

\section{Against a quality-sensitive account}

Cross-linguistically, the difference between heavy and light syllables is based on how many moras are in a given syllable: a heavy syllable contains two moras, and a light syllable has one. Hayes's (1989) Weight by Position parameter enables codas to present distinct moraicity, subject to languagespecific settings. For example, Khalkha Mongolian (Walker 1995) treats syllables with long vowels as heavy and those with short vowels as light, regardless of whether they are closed by a coda or not. In contrast, Latin (Levin 1985) considers syllables with long vowels or a short vowel plus a coda heavy (e.g., CVV and CVC), while open syllables with short vowels are light (e.g., CV). Other languages make weight distinctions solely based on vowels quality (the so-called quality-sensitive stress), or have ternary distinctions in weight. In some languages (such as Classical Greek), syllables closed by sonorants are heavy. Morén (1999) also offers a survey of distinct weight among consonants, which does not necessarily correlate to sonority. For example, Hausa (Newman 1997) shows distinctive weight 
for more sonorous consonants, but Chechen (Nichols 1997) has distinctive weight for less sonorous consonants only. A typological survey of weight criteria can be found in Gordon (2006), which further explores the correlation between phonological weight and phonetic energy.

Stress in Piuma Paiwan has previously been analyzed as qualitysensitive (Chen 2009) or sonority-driven (Yeh 2011a), so that the location of stress is determined by either quality (Kenstowicz 1997) or sonority (De Lacy 2004). In other words, stress is conjectured to search for more sonorous vowels within the domain, based on its preference for /i u a/ and dispreference for schwa in stress assignment. However, the problem with such previous accounts is that they do not adequately address the pattern of stress assignment in words with schwa in the last two syllables. Chen $(2006,83)$ mentions that "the right edge position must dominate the constraint of left edge for quality-sensitive stress to get a final stressed schwa" in CəСəC words like [tsə.kə́K] 'spouse', but without providing an explanation or formal analysis. In addition, she points out that the "penult is the most prominent position for Central Paiwan stress, but the right edge of a prosodic word becomes the optimal position for stress among equally prominent vowels in the quality-sensitive stress system", yet this statement conflicts with the fact that words with identical peripheral vowels /i u a/ still display penultimate stress (e.g., [ká.ma] 'father', [pú.nuq] 'brain', and [kí.kip] 'eyelash'). Yeh's (2011a, 122) analysis adopts a set of hierarchical constraints targeting metrical peaks as well as the constraint ${ }^{*} \mathrm{Ft} / \partial$, which penalizes every schwa in the foot. Yet ${ }^{*} \mathrm{Ft} / \partial$ alone is sufficient to account for the data provided in Yeh without invoking the ranking regarding sonority. With *Ft/o outranking FTBIN, this language would parse a degenerate foot rather than a disyllabic one when the vowels in the metrical window are both schwa. However, such an analysis is unable to account for the new data presented later in this study. Therefore, the claim that stress in Piuma Paiwan is driven by vowel sonority (or quality) is here called into question.

This study thus argues that the aforementioned communalects do not have quality-sensitive or sonority-driven stress for two reasons: first, the pattern of stress in words with vowels of the same sonority is distinct from those in the languages surveyed in Kenstowicz (1997) and De Lacy (2004). Second, the contrasting pattern of stress in Paiwan of CəCə́C versus Cə́Cə, which has never been mentioned previously, is evidence against the qualitysensitive analysis.

To show that Paiwan does not display quality-sensitive stress, it is essential to show how it differs from a language with true quality-sensitivity. 
Takia (Ross 2002), an Austronesian language spoken in North New Guinea, presents a stress pattern genuinely driven by vowel sonority (or vowel quality). With a sonority scale based on vowel height, $a>e, o>i$, $u$, stress in Takia must fall on the most sonorous vowel available in the last two syllables, as shown in (11). In (11a), stress searches for the more sonorous vowel in the last two syllables; thus [a] is most favored, then [e] and [o]. High vowels [i] and [u] are the least preferred residence for stress. When both vowels in the domain are of equal sonority, unmarked final stress emerges, as shown in (11b).

(11) a. V with different sonority [nisánes] 'hawk' [ábi] 'garden' [bugugáru] 'twins' [ifunó] 's/he hit you' [mulmól] 'a kind of tree' b. V with the same sonority [tamán] 'father (3SG)' [ifiní] 's/he hit him' [tubún] 'his/her grandparent'

It is evident that the default stress position for Takia is the final syllable, and stress moves to the penultimate syllable only for a more sonorous vowel. At first glance, Paiwan appears to be similar: the default position for stress is the penultimate syllable, and stress moves to the final syllable only for more sonorous vowels, as can be seen in (12). Yet a major problem emerges when words with schwas in both the penult and ultima are considered, as stress falls on the penultimate syllable in words such as $\mathrm{CíCi}(\mathrm{C}), \mathrm{CúCu}(\mathrm{C}), \mathrm{CáCa}(\mathrm{C})$ as in (13), but not CəCáC as in (14a). If Paiwan stress is sensitive to vowel quality or sonority, words with equally sonorous vowels such as $\mathrm{C} ə \mathrm{C} ə \mathrm{C}$ should receive penultimate stress, just like $\mathrm{CáCa}(\mathrm{C})$. The contrast between CəCáC and CáCə shown in (14) further suggests that closed and open syllables are crucially dissimilar when the nucleus is a schwa.

(12) a. Without schwa

$$
\begin{array}{ll}
\text { [vú.das] } & \text { 'sand' } \\
\text { [sá.fiq] } & \text { 'ant' } \\
\text { [pí.cu] } & \text { 'seven' }
\end{array}
$$

b. Final schwa [t̛́.qəv] 'lid' [Кí.cəq] 'sap' [lú.səq] 'tear' c. Penultimate schwa

$$
\text { [sə.má] 'tongue' }
$$

[cə.vús] 'sugarcane'

[kə.Rí $]$ 'sparrow'

(13) Words with identical peripheral vowels
a. dáva 'female friend'
d. yújus 'nose'
b. lumámad 'infant'
e. sízi 'goat'
c. lúkuts
'bird's nest fern'
f. míqi
'cheek' 
(14) Words with schwa

a. Final closed syllable

$\begin{array}{ll}\text { [tə.kə́ } \Lambda] & \text { 'spouse' } \\ \text { [tə.mə́l] } & \text { 'grass' } \\ \text { [və.tə.qə́l] } & \text { 'short necklace' } \\ \text { [və.Кə.vá } \Lambda] & \text { 'banana' }\end{array}$

b. Final open syllable

[l’́.fə] 'thin'

[Ка.Кว.Кə] 'plant species'

[sa.kó.yə] female name

[mu.d’́.qə] 'fattened (animals)'

Thus, a syllable consisting of schwa and a coda is heavier than an open syllable with schwa, thereby creating the conditions under which stress is attracted to final position. This idea is borne out by the fact that default penultimate stress emerges when the penult and ultima are equivalent - including when both end in schwa/ə/. The above pattern implies that schwa is so weak that, though normally disregarded, weight carried by a coda consonant can influence its ability to carry stress. In other words, a coda consonant's gained weight bolsters the relatively weak schwa nucleus, resulting in the condition that $\mathrm{C} ə \mathrm{C}$ is more suitable as a stress bearer than Cə. Codas following full vowels / i u a/ do not end up contributing weight to the syllable; therefore, they only become relevant to weight when needed. Morén (2000) indicates that such coerced weight is due to a restriction on minimal or maximal moraicity at surface. His analysis of Kashmiri shows that a closed syllable is forced to be heavy if it is the best potential syllable to bear stress in a word; otherwise coda consonants are analyzed as non-moraic. ${ }^{9}$

The scale of syllable weight in the Paiwan communalects is here posited to consist of a three-way distinction, $\mathrm{CVV}(\mathrm{C})>\mathrm{CV}(\mathrm{C}), \mathrm{Cə} \mathrm{C}>$ Cə. $\mathrm{CVV}(\mathrm{C})$ refers to diphthongs and coalesced syllables derived from two underlying vowels. A $\mathrm{CVV}(\mathrm{C})$ syllable at the right edge drags stress to final position; therefore, it is assumed to be bimoraic and heavier than a penultimate CV syllable. CV and CVC syllables can be understood to be of the same weight because stress falls on the penultimate syllable regardless of whether the ultima is $\mathrm{CV}$ or CVC. That is to say, coda consonants do not play any role in the scale of syllable weight when the syllable nucleus is a peripheral vowel. In that case, the presence or absence of a coda con-

${ }^{9}$ Morén (2000) examines the interaction between vowel length, consonant weight, and stress. Kashmiri stress is determined by syllable weight; it falls on the leftmost syllable in words with short vowels (e.g., [kú.ni.vi.zi] 'sometime'), on the leftmost long vowel if available (e.g., [mo.ki.láa.vun] 'balcony'), or the leftmost closed syllable (e.g., [jóm.bir.zal] 'narcissus'). If the conclusion that closed syllables are heavy is made, the puzzle then appears: the leftmost long vowel is stressed when both long vowels and closed syllables are present, e.g., [vah.ráa.vun] 'to spread'. Thus the coda consonant is coerced to carry weight only when the syllable is stressed. 
sonant makes no difference, as in [kí.na] 'mother' versus [vú.das] 'sand'. However, in words with schwa in both of the last two syllables, CəC is treated as heavier than Cə because the former attracts stress to itself in final position when paired with a penultimate Cə, while Cə does not, as in [lə.sə́q] 'tear', versus [lá.fə] 'thin' in (14). Note that coda consonants following schwa are forced to bear weight only in word-final position, not in word-medial position. This is due to the lack of word-internal codas as in ${ }^{*} \mathrm{CəC}$.CəC , since they are highly restricted as mentioned in Section 2. Of course, the distinction in coda consonant weight only emerges due to the crucial existence of the asymmetry between / $\mathrm{i} \mathrm{u} \mathrm{a/} \mathrm{and} \mathrm{schwa} \mathrm{/} \mathrm{/} \mathrm{/,} \mathrm{as}$ shown in (5), which distinguishes the communalects under consideration from the rest of Paiwan. In the relevant communalects, CV is heavier than Cə, so stress avoids a penultimate schwa and instead lands on the final syllable, as in [sə.má] 'tongue' and [qə.zún] 'window'. This analysis further proposes that $\mathrm{CV}(\mathrm{C})$ and $\mathrm{CəC}$ in the two-syllable domain share a position on the weight scale, as there is no positive evidence showing that $\mathrm{CV}(\mathrm{C})$ is heavier than $\mathrm{CəC}$ due to the unavailability of words like ${ }^{*} \mathrm{CəC} \cdot \mathrm{CV}(\mathrm{C})$.

It is here conjectured that schwa's special behavior is due to its inherent weakness and lack of a complete mora, what disqualify it from being stressed. In (15a), both diphthongs and coalesced vowels are bimoraic because of their underlying properties - they preserve two moras from the underlying vowels. (15b) shows that single vowels / $\mathrm{i} \mathrm{u} \mathrm{a/} \mathrm{carry} \mathrm{a} \mathrm{single}$ mora. A schwa alone, on the other hand, takes a weak mora, shown in (15d). As mentioned in Kager's (1990) analysis of stress in Dutch, schwa is commonly treated as non-moraic in Moraic Theory (Hyman 1985; McCarthy \& Prince 1986/1996; Hayes 1989), which predicts schwa's inability to receive stress. However, this study does not follow Kager's account of schwa as non-moraic, due to its ability to be stressed in Paiwan under specific circumstances: though it generally resists stress, schwa can be the foot head, e.g., [lá.fə] 'thin'. For schwa to be assigned a defective mora reinforces its phonological weakness as compared to other vowels, but also differentiates it from truly non-moraic elements such as consonants. In (15c), a schwa is able to share a full mora with a coda consonant. Although a coda consonant does not contribute weight to a syllable when following /i u a/, it does when schwa has to be the stress-bearer, and helps to fulfill the minimal requirement of a stressed syllable that is the head of a foot. Furthermore, it is inappropriate to assume that CVC and CV are bimoraic and Cə is lighter with a single mora, as in Ulfsbjorninn's (2017) 
analysis of Hawu (another Austronesian language), ${ }^{10}$ because Paiwan has genuine bimoraic heavy syllables in the form of diphthongs and coalesced vowels derived from underlying hiatus, which it favors over CVC and CV in stress assignment. Therefore, the moraic status of a coda is subject to the quantity of the nucleus vowel and whether it is stressed, leading to the three-way distinction presented above: $\mathrm{CVV}(\mathrm{C})>\mathrm{CV}(\mathrm{C}), \mathrm{CəC}>\mathrm{C}$.

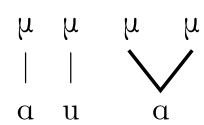

b. $\mu$

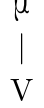

c.

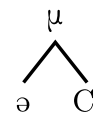

d. $\mu_{\text {weak }}$

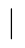

ə

The pattern of stress and the weight system of these Paiwan communalects may seem to resemble those of Javanese and other Malayic languages, in which syllables with schwa (or reduced vowels) are light. Stress in Javanese is confined to the last two syllables of a word: stress falls on the penultimate syllable if it has a full vowel, and otherwise on the ultima if the penult contains a schwa (Ras 1982), though some scholars differ on this point. Poedjosoedarmo (1982) claims that stress is final in Javanese, while Goedemans and van Zanten (2007) show that there are no phonetic correlates for stress and listeners equally accept stress on the penult or ultima. However, Javanese does not have long vowels or diphthongs, and unlike Paiwan, a sequence of vowels is always hetero-syllabic. Therefore, only a binary distinction in syllable weight is sufficient to account for Javanese stress: syllables containing schwas are light, while others are heavy.

\section{An OT analysis}

In Paiwan, the location of stress is confined to the rightmost two syllables of a prosodic word, and penultimate stress is the overwhelming pattern seen in the data above. No secondary stress is observed. It is apparent that Paiwan usually parses a single left-headed (trochaic) foot at the rightmost edge; thus, the constraint ALL-FT-Right must be dominant, requiring a prosodic word to have only one foot at the right edge. As the default position of stress is the penultimate syllable, FTFORM = TrOCHAIC (henceforth TROCH) must also be ranked high, and in particular, higher than IAMB;

${ }^{10}$ Hawu (a Malayo-Polynesian, Austronesian language) is analyzed as a quantity sensitive language, in which schwa /o/ carries a mora, and other vowels /a e i o u/ dominate two moras in stressed position (Ulfsbjorninn 2017). This language has neither long vowels nor diphthongs, and such analysis is tenable based on evidence from lenition, metathesis, and the fact that schwa is restricted to stressed position. 
however, it could be overridden by more important requirements. Feet are binary branching; thus, a foot which includes many syllables is never automatically better. The relation can be captured by the ranking FTBIN $\gg$ PARSYL. The ranking for general stress is shown in (16) and (17).

(16) Stress: All-Ft-Right »Ft-Bin, Troch » Par-Syl, Iamb

a. All-Ft-Right: Every foot stands at the right edge of the prosodic word.

b. FT-Bin: Feet are binary under moraic or syllabic analysis.

c. Troch (TrocheE): Feet are left-headed.

d. PARSyl: Syllables are parsed by feet.

e. IAMB: Feet are right-headed.

Furthermore, syllables derived from underlying vowel hiatus are heavier than others, and according to the weight scale $\mathrm{CVV}(\mathrm{C})>\mathrm{CV}(\mathrm{C})$, stress is assigned to the bimoraic syllable of a foot. WeIGHT-TO-SRESS PRINCIPLE (WSP), which makes sure that heavy syllables obtain stress, must therefore be undominated. That stress favors / $\mathrm{i} \mathrm{u} \mathrm{a/} \mathrm{over} \mathrm{/} \mathrm{/} \mathrm{/,} \mathrm{together} \mathrm{with}$ other restrictions on schwa in Paiwan, implies that syllables with schwa are weaker than those with peripheral vowels as a foot head. The constraint FtHead-Minimality (HD-Min) requires the size for a foot head to be at least a full mora, and penalizes every stressed syllable with a single schwa. With this constraint ranked high, stress seeks out a better syllable nucleus in the domain. Coda consonants are usually non-moraic. They add weight to the syllable only when the nucleus is a schwa / / / and has to carry stress, as the contrast between Cá.Cə and Cə.CáC has shown. Therefore, *Mora[C] outranks WeIght-BY-Position (WBP), showing that coda consonants generally do not take a mora. With HD-Min ranked above $*$ Mora $[\mathrm{C}]$, a coda consonant becomes moraic only when it helps a syllable to satisfy the minimal requirement of a foot head. Constraints regarding weight sensitivity are shown in (18), and tableaux (19)-(21) illustrate the interaction.

\begin{tabular}{|l|c|c|c|c:c|}
\hline Input: /lumamad/ & ALL-Ft-RIght & TROCH & FT-BiN & PARSYL & IAMB \\
\hline a. (u. (má.mad) & & & & $*$ & $*$ \\
\hline b. (lu).(má.mad) & $* * !$ & & $*$ & & \\
\hline c. lu.(ma.mád) & & $* !$ & & & \\
\hline d. (lú.ma.mad) & & & $* !$ & & \\
\hline
\end{tabular}


(18) Weight sensitivity: WSP, HD-MIN $\gg * \operatorname{MorA}[\mathrm{C}] \gg \mathrm{WBP}$

a. Weight-To-Stress Principle (WSP): Heavy syllables are stressed.

b. Fthead-Minimality (HD-Min): The head of a foot must contain at least a full $\operatorname{mora}(\mu)$.

c. ${ }^{*} \operatorname{MorA}[\mathrm{C}]$ : Do not associate a mora with a consonant.

d. Weight-By-Position (WBP): Coda consonants must surface as moraic.

e. Foot-Minimality (Ft-Min): a foot must be at least bimoraic or disyllabic.

Tableau (19) shows that the heavy syllable in a foot must obtain stress in words with underlying hiatus. ${ }^{11}$

\begin{tabular}{|l|c:l|l|l|}
\hline Input:/sikau/ & WSP & HD-MIN & ${ }^{*}$ MorA[C] & WBP \\
\hline a. $\left(\mathrm{si}_{\mu} \cdot \mathrm{ka}_{\mu} \mathrm{w}_{\mu}\right)$ & & & & \\
\hline b. $\left(\mathrm{si}_{\mu} \cdot \mathrm{ka}_{\mu} \mathrm{w}_{\mu}\right)$ & $* !$ & & & \\
\hline
\end{tabular}

For words with an open penult containing schwa and an ultima containing a peripheral vowel, stress shifts to the final syllable because schwa is unable to satisfy the size of a stressed syllable. In tableau (20), stress in candidate (c) falls on the penultimate schwa, rather than the final syllable with a full vowel, therefore it violates HD-MiN and is ruled out. The coda of candidate (b) is moraic at the expense of a fatal violation of higher-ranked *MorA $[\mathrm{C}]$, thus candidate (a), with a non-moraic coda which violates a low-ranked WBP, is optimal. For words with schwas in both of the last two syllables in (21), stressing the penultimate schwa in candidate (c), or the final schwa with a non-moraic coda in candidate (b), violates high-ranked HD-MIN. Although candidate (a) violates *MorA[C] by adding a mora to the coda consonant, it satisfies the higher HD-Min because a schwa plus a moraic coda qualifies to be a foot head. Therefore, candidate (a) is the optimal.

The ranking combining stress and weight sensitivity is as follows: All-Ft-R, WSP, HD-Min $\gg$ FT-BIn, Troch, ${ }^{*}$ Mora $[\mathrm{C}] \gg$ PAR-SYL $\gg$ IAMB, WBP. Since AlL-FT-R is undominated and IAMB is low-ranked, they are omitted from the following tableaux in the interests of space. In tableau (22), the penultimate and final nuclei are peripheral vowels. Adding a mora to coda in candidate (b) or having stress on the last syllable does not result in an acceptable form. Therefore, candidate (a) with

${ }^{11}$ Details on the interactions between vowel hiatus and relevant constraints on syllables can be found in Yeh (2011a), including how glide formation and coalescence occur and the preservation of underlying moras. 
(20)

\begin{tabular}{|l|c:c|c|c|}
\hline Input:/cəvus/ & WSP & HD-MiN & ${ }^{*}$ MORA[C] & WBP \\
\hline a. (cə.vús) & & & & $*$ \\
\hline b. (cə.vús $\mu$ ) & & & $* !$ & \\
\hline c. (có.vus) & & $* !$ & & $*$ \\
\hline d. (cə́.vus $\left.{ }_{\mu}\right)$ & $* !$ & $*$ & $*$ & \\
\hline
\end{tabular}

(21)

\begin{tabular}{|c|c|c|c|c|}
\hline Input:/təməl/ & WSP & HD-MIN & ${ }^{*} \operatorname{MorA}[\mathrm{C}]$ & WBP \\
\hline a. $\nleftarrow($ təo.mólu & & & * & \\
\hline b. (tீə.mól.) & & $* !$ & & $*$ \\
\hline c. (†’’.məl) & & $* !$ & & * \\
\hline
\end{tabular}

penultimate stress wins out. In tableau (23), the penultimate nucleus is a schwa but the final one is not. Having schwa as the foot head violates high-ranked HD-Min in candidate (c). Though candidates (a) and (b) both incur a violation of TROCH, the moraic coda of (b) has one more violation at the same rank. The most competitive candidate $(\mathrm{d})$ violates another constraint * MoRA $[\mathrm{C}]$ of the same rank as candidate (a) does, but it incurs an additional violation by parsing a single syllable into a foot; therefore, candidate (c) is ruled out. It is thus apparent that coda consonants are nonmoraic, and assigning a mora to a coda does not improve a candidate's chances when the preceding nucleus is a peripheral vowel $/ \mathrm{i} \mathrm{u} \mathrm{a} /$.

\begin{tabular}{|c|c|c|c|c|c|c|c|}
\hline Input:/vudas/ & WSP & HD-MiN & FT-BIN & TROCH & ${ }^{*}$ Mora $[\mathrm{C}]$ & PARSYL & WBP \\
\hline a. $\odot$ (vú.das) & & & & & & & * \\
\hline b. (vú.das $\left.{ }^{\prime}\right)$ & $* !$ & & & & * & & \\
\hline c. (vu.dás) & & & & $* !$ & & & * \\
\hline
\end{tabular}

\begin{tabular}{|c|c|c|c|c|c|c|c|}
\hline Input:/cəvus/ & WSP & HD-MiN & FT-BIN & Troch & ${ }^{*}$ Mora $[\mathrm{C}]$ & PARSYL & WBP \\
\hline a. (cə.vús) & & & & * & & & * \\
\hline b. $\quad\left(\right.$ cə.vús $\left._{\mu}\right)$ & & & & * & $* !$ & & \\
\hline c. (cá.vus) & & $* !$ & & & & & * \\
\hline d. $\quad$ cə. $\left(\right.$ vús $\left._{\mu}\right)$ & & & & & * & $* !$ & \\
\hline
\end{tabular}


Though it does not ameliorate syllables with peripheral vowels, the weight of a coda consonant is still crucial to the contrast CəCáC versus CáCə because it is able to rescue a syllable with schwa from being a disqualified foot head. Since there is no coda consonant to help in CáCə, the penultimate schwa forces itself to bear stress. In tableau (24), candidates (b) and (c) violate dominant HD-Min because the stressed syllable only carries a weak mora. Although candidate (d) has a moraic coda, which violates *Mora $[\mathrm{C}]$, a weak schwa together with a moraic coda still fails to satisfy the bimoraic requirement of a foot-undominated FT-Min. Both FT-Bin and FT-Min are thus necessary: the former only examines whether a foot is binary branching, and the latter only requires a minimum size for a foot (either two moras or two syllables). Therefore, a foot like (mól ${ }_{\mu 1}$ ) in (24d) satisfies FT-BIN with a left-branching schwa and a right-branching moraic coda, but fails to fulfill the basic bimoraic size.

\begin{tabular}{|c|c|c|c|c|c|c|c|c|}
\hline Input:/təməl/ & FT-MiN & WSP & HD-MIN & FT-BIN & TROCH & ${ }^{*}$ Mora $[\mathrm{C}]$ & PARSYL & WBP \\
\hline a. $\varpi\left(\mathfrak{t g} \partial . \mathrm{mó}_{l_{\mathfrak{l}}}\right)$ & & & & & * & * & & \\
\hline b. (tๆə.mə́l) & & & $* !$ & & * & & & * \\
\hline c. $\quad\left(\mathrm{t}^{\prime} \partial \cdot \mathrm{m} \cdot \mathrm{l}\right)$ & & & $* !$ & & & & & * \\
\hline d. $\quad$ tə. $\left(\left.m a ́\right|_{11}\right)$ & $* !$ & & & & & * & * & \\
\hline
\end{tabular}

In words with schwa in open syllables, no coda consonants are available to help, and Paiwan does not lengthen the vowel or assign a mora to the onset, so the unmarked penultimate stress emerges. In tableau (25), the monosyllabic foot of candidate (c) incurs a fatal violation of FT-Min. Though both candidates (a) and (b) violates HD-MIN, (a) wins out because of its trochaic foot. The ranking of weight sensitivity, HD-MIN $\gg{ }^{*}$ MorA $[\mathrm{C}] \gg$ WBP, along with other metrical constraints, illustrates that coda consonants are non-moraic, and become moraic only when needed.

\begin{tabular}{|c|c|c|c|c|c|c|c|c|}
\hline Input:/əə.əə/ & FT-MiN & WSP & HD-MIN & FT-BIN & TROCH & ${ }^{*} \operatorname{Mora}[\mathrm{C}]$ & PARSYL & WBP \\
\hline a. $\sigma($ lá.fə) & & & * & & & & & \\
\hline b. (lə.f̧́) & & & $*$ & & $* !$ & & & \\
\hline c. lə.(抍 & $* !$ & & * & * & & 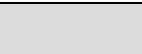 & * & \\
\hline
\end{tabular}

An alternative analysis provided by an anonymous reviewer adopting the constraint ${ }^{*}$ Footed/a and a more stringent high-ranked *STRESSED/o should also be considered. While *Footed/ə penalizes every schwa in a foot, ${ }^{*}$ STRESSED/a punishes every stressed schwa. When these are added to 
the metric constraints, the ranking is as follows: ALL-FT-R, ${ }^{*}$ StresSED /ə $\gg$ Trochee, ${ }^{*}$ Footed/ə, FT-BIn $\gg *$ Mora $[\mathrm{C}] \gg$ WBP, IAMB. Undominated ALL-FT-R and low-ranked IAMB are omitted in tableaux for space. In words with peripheral vowels in the last two syllables, TROCH $\gg$ IAMB and ${ }^{*}$ MorA $[\mathrm{C}] \gg$ WBP ensures that a trochaic foot is more optimal and the coda consonant is not assigned weight, as shown in (26).

\begin{tabular}{|c|c|c|c|c|c|c|}
\hline Input:/ $\mathrm{CaCaC} /$ & *STRESS/ə & Troch & *FoOT $/$ ə & FT-BIN & ${ }^{*}$ Mora $[\mathrm{C}]$ & WBP \\
\hline a. (Cá.CaC) & & & & & & $*$ \\
\hline b. (Ca.CáC) & & $* !$ & & & & * \\
\hline c. Ca. $\left(\right.$ Cá $\left.{ }_{\mu}\right)$ & & & & & $* !$ & \\
\hline
\end{tabular}

When both syllables contain a schwa and the word-final syllable is closed as shown in (27), candidate (a), which parses fewer schwas into the foot, is more optimal because it has fewer violations of *FooTed/ə. Furthermore, the coda is still assigned weight in order to satisfy FT-Bin. For words with schwa in open syllables as in (28), candidate (a) violates FT-BIN without the help of a moraic coda, and candidate (b)'s inclusion of two schwas in the foot incurs two violations of ${ }^{*} \mathrm{FoOTED} / \mathrm{\partial}$, so the candidates tie at that rank. Candidate (a) can be ruled out by a low-ranked PARSYL because it parses only one syllable into the foot, leaving the other syllable unparsed.

\begin{tabular}{|c|c|c|c|c|c|c|}
\hline Input:/CəCəC/ & *StREsS/a & TROCH & *FOOT/ə & FT-BIN & ${ }^{*}$ Mora $[\mathrm{C}]$ & WBP \\
\hline a. Сə. $\left(\right.$ Cə́C $\left.{ }_{\mu}\right)$ & * & & * & & * & \\
\hline b. (Cə́.CəC) & * & & $* * !$ & & & $*$ \\
\hline c. (Cə.Сə́C) & * & * & $* ! *$ & & & * \\
\hline
\end{tabular}

(28)

\begin{tabular}{|c|c|c|c|c|c|c|c|}
\hline Input:/СəСə/ & *STRESS/a & TrOCH & *FOOT/ə & FT-BIN & ${ }^{*}$ MORA $[\mathrm{C}]$ & WBP & PARSYL \\
\hline a. Сə.(Cә́) & * & & * & * & & & $* !$ \\
\hline b. $\circledast$ (Cá.Cə) & * & & $* *$ & & & & \\
\hline c. (Cə.Cá) & * & * & **! & & & & \\
\hline
\end{tabular}

Note that when the penultimate syllable contains a schwa, and the last syllable has a full vowel with a coda like CəCVC, the candidate parsing a monosyllabic foot with a moraic coda wins out, as candidate (a) does in tableau (29). 
(29)

\begin{tabular}{|c|c|c|c|c|c|}
\hline Input:/CəCaC/ & *STRESS/ə & Troch & $\begin{array}{l:l}\text { *FOOT/ə } & \text { FT-BIN }\end{array}$ & $*$ MorA $[\mathrm{C}]$ & WBP \\
\hline a. ${ }^{\circ}$ С. $\left(\mathrm{CáC}_{\mu}\right)$ & & & I & $*$ & \\
\hline b. (Cá.CaC) & $* !$ & & $*$ & & $*$ \\
\hline c. (Cə.CáC) & & $* !$ & $*$ & & $*$ \\
\hline d. Cә.(CáC) & & & $* !$ & & * \\
\hline
\end{tabular}

Thus, this analysis also accounts for the data presented here. However, it does not capture the intuition that a coda consonant following a schwa is assigned a mora due to the weak status of its own nucleus. Instead, the assignment of a mora to the coda consonant is a workaround designed to avoid parsing an additional schwa in the foot, as shown by the optimal candidates Сə. $\left(\mathrm{Cá}_{\mu}\right)$ and Сə. $\left(\mathrm{CáC}_{\mu}\right)$ in $(27)$ and (29) respectively: with the ranking of the schwa-penalizing constraint ${ }^{*}$ STRESSED/ə $\gg{ }^{*}$ Footed/a and the weight-sensitive constraints *MORA $[\mathrm{C}] \gg \mathrm{WBP}$, a coda consonant is forced to be moraic to circumvent violations of FT-BIN and*Foot/a, since to parse fewer schwas into the foot results in FT-BIN violations. Thus the coda of the last syllable becomes moraic because of the schwa in the penultimate syllable, rather than due to the more intuitive influence of its own nucleus.

\section{Discussion and conclusions}

To recap, the patterns in these Paiwan communalects show generally penultimate stress, unless the penultimate vowel is a schwa or the final syllable is heavy. In these cases, stress shifts to the final syllable. If both vowels within the two-syllable domain at the right edge are schwa, stress falls on a final closed syllable; otherwise, stress is assigned to the penultimate schwa. Many other languages also display such a stress pattern, wherein a weaker vowel or a lighter syllable resists stress, instead shifting it to a better or heavier syllable nearby. For example, in Dutch, schwa cannot take stress, and also behaves differently from other vowels in its distribution relative to other segments and the application of certain phonological rules; e.g., consonant clusters before schwa cannot comprise a complex onset (Kager 1989). This type of pattern is also common in some Austronesian languages (Goedemans et al. 2010). For example, Malay has penultimate stress unless the penultimate vowel is schwa followed by a single consonant, in which case stress is final (Winstedt 1927; Lewis 1947). An identical stress rule 
has also been reported for Iban (Richards 1981). Asmah $(1981,41)$ points out that in Malay and Iban, schwa, which occurs only in pre-final syllables, is never stressed in open syllables (Blust 2007). In Karo Batak, stress falls on the penultimate syllable unless it contains an open schwa and the final does not (Woollams 1996). In addition, in Lamaholot (Arndt 1937) and Kulamanen (Dubois 1976), stress falls on the penultimate syllable, unless its vowel is a schwa and the final vowel is a full vowel. Moreover, in Wolff's $(1993,1)$ reconstruction of Proto-Austronesian (PAN) stress, he mentions that PAN stress fell on the penult of the root if it was long or accented, and on the final syllable if the penult was short or unaccented. It is therefore not surprising to see that stress shifts between the last two syllables, looking for a more qualified syllable in some Austronesian languages, since they might inherit the property from PAN. In comparison to languages in which schwa (or any central vowel) avoids carrying stress, as in Dutch or Indonesian (Cohn \& McCarthy 1994/1998), the noteworthy point about Paiwan lies in the fact that schwa is still able to take stress in both open and closed syllables when there is no alternative available, even though schwa is generally dispreferred as a stress-bearer. More interestingly, other communalects of Paiwan that have the same distributional restrictions on schwa nevertheless treat schwa and other vowels the same with respect to stress. A comparison between the aforementioned and other Paiwan communalects may help to trace their historical development.

Another point to be considered is the system of syllable weight. In many languages where stress is sensitive to syllable weight, heavier syllables tend to attract stress, whereas lighter syllables avoid being stressed (Hyman 1985; Hayes 1995). Of course, languages differ in how they categorize different syllable structures, especially the weight of consonants. Some languages treat CVV as heavy, and CVC and CV as light; others consider CVV and CVC heavy, but CV light; and yet other languages have more detailed systems of distinction. In some languages, only a category of consonants bear weight. After surveying many languages with quality-sensitive stress, Gordon (2002) offers a typology of phonological weight distinction, and argues that weight systems closely match phonetic and perceptual parameters of total energy. His study further suggests that "phonological weight distinctions are ultimately predictable from other basic phonological properties, such as syllable structure" (op.cit., 51). In the present re-examination of the data from Paiwan, several relevant factors serve to connect the new analysis to the historical analysis of Austronesian referred to above: (i) schwas are phonetically shorter than other vowels, (ii) schwas seldom end a word (though they are not forbidden from doing 
so), and (iii) schwas barely occur within independent monosyllabic words, whereas other vowels do, e.g., vat 'rice', tu 'burning charcoal', djix 'buttock'. The weight of schwa may thus be predicted from these patterns, as well as from the interactions between schwa and neighboring segments. As pointed out by Blust $(2007,28)$, "the inherited Austronesian schwa is extra-short, and in general cannot hold a stress unless it geminates a following consonant. If gemination does not occur, stress generally shifts one syllable to the right." It is suspicious that a schwa can take stress only when combined with a geminate, which is often assumed to be longer or heavier. The weight system must play a role in the structure of syllables.

To sum up, this study argues that stress in these Paiwan communalects is sensitive to quantity not only the heaviness of bimoraic syllables, but also the weakness of schwa and the variable weight of its coda. Schwa is dispreferred from being stressed due to its weak property, so a coda consonant is coerced to contribute weight only when following a schwa, based on the contrast between $/ \mathrm{i} \mathrm{u} \mathrm{a/}$ and /ə/, and the distinction between Cə and $\mathrm{CəC}$ syllables. Schwa is assumed to carry a weak mora, which aligns with the weak properties it is observed to have in many other languages (Gordon et al. 2012). In addition, the requirements for a well-formed foot head result in the avoidance of stressed schwa; only a moraic coda consonant rescues it from its plight. The pattern of stress in the aforementioned communalects can thus be accounted for by referring to syllable quantity.

\section{Acknowledgements}

I would like to express my gratitude to Prof. Hui-chuan J. Huang and the two anonymous reviewers for giving me helpful and detailed comments. I thank my consultants for sharing their language with me. Some ideas of this paper were presented at OCP-12 in Barcelona in 2015, and OCP-13 in Budapest in 2016, and I am grateful to the audience for their comments and discussions. Parts of the research reported has been supported by National Science Council of Taiwan (NSC 102-2410-H-017-007).

\section{References}

Arndt, Paul P. 1937. Grammatik der Solor-Sprache. Ende, Flores, Indonesia: ArnoldusDrukkerij.

Asmah, Haji Omar. 1981. The Iban language of Sarawak: A grammatical description. Kuala Lumpur: Dewan Bahasa dan Pustaka.

Blust, Robert. 2007. Disyllabic attractors and anti-antigemination in Austronesian sound change. Phonology 24. 1-36. 
Chen, Chun-Mei. 2006. A comparative study on Formosan phonology: Paiwan and Budai Rukai. Doctoral dissertation. University of Texas at Austin.

Chen, Chun-Mei. 2009. The phonetics of Paiwan word-level prosody. Language and Linguistics 10. 593-625.

Cheng, Chunghua. 2016. The study of Paiwan dialects. Doctoral dissertation. Peking University.

Cohn, Abigail C. and John J. McCarthy. 1994/1998. Alignment and parallelism in Indonesian phonology. Working Papers of the Cornell Phonetics Laboratory 12. 53-137.

De Lacy, Paul. 2004. Markedness conflation in Optimality Theory. Phonology 21. 145-200.

Dubois, Carl D. 1976. Sarangani Manobo: An introductory guide. Manila: Linguistic Society of the Philippines.

Egli, Hans. 1990. Paiwangrammatik. Wiesbaden: Otto Harrassowitz.

Ferrell, Raleigh. 1982. Paiwan dictionary. Canberra: The Australian National University.

Goedemans, Rob, Harry van der Hulst and Ellen van Zanten. 2010. A survey of word accentual patterns in the languages of the world. Berlin \& New York: De Gruyter Mouton.

Goedemans, Rob and Ellen van Zanten. 2007. Stress and accent in Indonesian. In V. J. van Heuven and E. van Zanten (eds.) Prosody in Indonesian languages. Utrecht: Netherlands Graduate School of Linguistics. 35-62.

Gordon, Matthew. 2002. A phonetically driven account of syllable weight. Language 78 . $51-80$.

Gordon, Matthew. 2006. Syllable weight: Phonetics, phonology, typology. London \& New York: Routledge.

Gordon, Matthew, Edita Ghushchyan, Bradley McDonnell, Daisy Rosenblum and Patricia A. Shaw. 2012. Sonority and central vowels: A cross-linguistic phonetic study. In S. Parker (ed.) The sonority controversy. Berlin \& New York: Mouton de Gruyter. 219-256.

Hayes, Bruce. 1989. Compensatory lengthening in Moraic Phonology. Linguistic Inquiry 20. 253-306.

Hayes, Bruce. 1995. Metrical stress theory. Principles and case studies. Chicago: The University of Chicago Press.

Ho, Dah-an. 1977. The phonological system of Butanglu: A Paiwan dialect. Bulletin of the Institute of History and Philology 48. 595-618.

Ho, Dah-an. 1978. A preliminary comparative study of five Paiwan dialects. Bulletin of the Institute of History and Philology 49. 565-681.

Hyman, Larry M. 1985. A theory of phonological weight. Dordrecht: Foris.

Kager, René. 1989. A metrical theory of stress and destressing in English and Dutch. Dordrecht: Foris.

Kager, René. 1990. Dutch schwa in moraic phonology. Proceedings of Chicago Linguistics Society 26. 241-256.

Kenstowicz, Michael. 1997. Quality-sensitive stress. Rivista di Linguistica 9. 157-188.

Levin, Juliette. 1985. A metrical theory of syllabicity. Doctoral dissertation. MIT.

Lewis, Martha B. 1947. Teach yourself Malay. London: Hodder and Stoughton for the English University Press. 
McCarthy, John J. and Alan Prince. 1986/1996. Prosodic morphology I. Constraint interaction and satisfaction. Rutgers University Center for Cognitive Science Technical Report \#32.

McCarthy, John J. and Alan Prince. 1993. Prosodic morphology I. Constraint interaction and satisfaction. Rutgers University Center for Cognitive Science Technical Report $\# 3$.

Morén, Bruce. 1999. Distinctiveness, coercion and sonority: A unified theory of weight. Doctoral dissertation. University of Maryland at College Park.

Morén, Bruce. 2000. The puzzle of Kashmiri stress: Implications for weight theory. Phonology 17. 365-396.

Newman, Paul. 1997. Hausa phonology. In A. S. Kaye (ed.) Phonologies of Asia and Africa (including the Caucasus), volume 1. Winona Lake, IN: Eisenbrauns. 537-552.

Nichols, Johanna. 1. 1997. Chechen phonology. In A. S. Kaye (ed.) Phonologies of Asia and Africa (including the Caucasus), volume 2. Winona Lake, IN: Eisenbrauns. 941-971.

Poedjosoedarmo, Soepomo. 1982. Javanese influence on Indonesian. Canberra: RSPAS.

Prince, Alan and Paul Smolensky. 2004. Optimality Theory: Constraint interaction in Generative Grammar. Malden, MA \& Oxford: Blackwell.

Ras, Johannes Jacobus. 1982. Inleiding tot het modern javaans. 's-Gravenhage: Martinus Nijhoff.

Richards, Anthony. 1981. An Iban-English dictionary. Oxford: Clarendon.

Ross, Malcolm. 2002. Takia. In J. Lynch, M. Ross and T. Crowley (eds.) The Oceanic languages. London: Curzon Press. 216-248.

Ulfsbjorninn, Shanti. 2017. Lenition and metathesis in Hawu (now understood as a quantity sensitive language). Manuscript (http://ling.auf.net/lingbuzz/003296).

Walker, Rachel. 1995. Mongolian stress: Typological implications for nonfinality in unbounded systems. Phonology at Santa Cruz 4. 85-102.

Winstedt, Richard O. 1927. Malay grammar. Oxford: Oxford University Press.

Wolff, John U. 1993. Proto-Austronesian stress. In J. A. Edmondson and K. J. Gregerson (eds.) Tonality in Austronesian languages. Honolulu: University of Hawaii Press. 1-15.

Woollams, Geoffrey. 1996. A grammar of Karo Batak, Sumatra. Canberra: Australian National University.

Yeh, Shih-chi Stella. 2011a. Issues in Paiwan phonology. Doctoral dissertation. National Tsing Hua University, Taiwan.

Yeh, Shih-chi Stella. 2011b. Phonemic distinction between vowels and glides in Sinvaudjan Paiwan. Tsing Hua Journal of Chinese Studies 41. 551-586. 